\title{
DPC- SVM of DFIG Using Fuzzy Second Order Sliding Mode Approach
}

\author{
Farida Mazouz* (iD), Sebti Belkacem*iD, Ilhami Colak** (D) \\ *LEB, Department of Electrical engineering, Faculty of Technology, Batna-2 University, Mostefa Ben Boulaid, Batna, Algeria \\ **Department of Electrical engineering, Faculty of Technology, Nisantasi University, Istanbul, Turkey \\ (†F.mazouz@univ-batna2.dz, s.belkasem@univ-batna2.dz,ilhcol@gmail.com)
}

Received: 06.12.2021 Accepted:28.12.2021

\begin{abstract}
Conventional controller's methods, based on PI regulators, used as a direct power control (DPC) of the double feed induction generator (DFIG) are not robust enough in the face of parametric uncertainties and strong ripple of the powers. From the best evoked control techniques presented in this field to overcome these drawbacks, we will study some improvement variants such as the use of the second order sliding mode control (SOSMC) developed on the basis of the super twisting torsion algorithm (STA) associated with the fuzzy logic control to obtain (FSOSMC) in order to obtain acceptable performance. Finally, the effectiveness of the planned control system is studied using Matlab/Simulink. The proposed method reduces power ripples, improves driving dynamics by making it less sensitive to parameter uncertainty.
\end{abstract}

Keywords DFIG, DPC, SOSMC, FSOSMC, STA, Parametric Variations.

\section{Introduction}

The structures of wind power systems are more and more efficient. In addition to the mechanical characteristics of the wind turbine, the efficiency of converting mechanical energy into electrical energy is very important, [1]. Again, many devices exist and, for the most part, use synchronous and DFIG machines. The latter represents a new solution in the field of high power drives, in particular those requiring a wide range of operation at constant power, [2-3].

The DFIG, thanks to its dual power supply, offers several possibilities for reconfiguring the operating mode. Thus, it has good performance, either in over speed operation or in low speed operation. The converter-machine-control unit now allows flexibility, precision and reliability to be combined with today's energy saving imperatives. Joint advances in power electronics and digital electronics have made it possible to develop several controls approaches to control the operation of electrical machines in real time, [3].

Vector control (VC) by the stator flux orientation is the most widely used control technique in conjunction with the use of a general reference rotating frame. Since DFIG is used at the high power scale, the resistance of the stator becomes relatively very small, so it can be neglected. Therefore, the orientation of the stator flux can be replaced by an orientation of the stator voltage. This vector control technique is always an entry point for the design and for the analysis of the different modes of operation. In a synchronous frame of reference, the decoupling of the rotor currents leads to a decoupling of the active and reactive powers. Indeed, in the case of an orientation of the stator flux of the DFIG, the quadrature component of the current controls the active power and the direct component control the reactive power, [4]. This dependence is the opposite in the case of an orientation of the stator voltage. However, the performance of regulation which uses proportional-integral (PI) type correctors relies heavily on precise knowledge of machine parameters. However, the dependence on the parametric variation degrades the performance of the control when the electrical and mechanical parameters of the DFIG are varied, [5].

The second families of controls are relatively recent under the name of Direct Torque Control (DTC), [6]. This type of control is able to control both the torque of the machine as well as its flux in an even more precise, faster and more robust way, compared to the vector control, and thus, with a simplified control algorithm and less dependent on machine parameters. Direct Power Control (DPC) follows the same philosophy as DTC, [7-9]. It has the merit of being more advantageous for the control of the powers of the DFIG, having a low computational complexity, a fast transient response and a low dependence on the model of the 
machine. However, unlike vector control, the states of the power switches are determined instantly by comparing references with measurements without resorting to pulse width modulation. Thus, although this control is less dependent on the parameters of the system, it lacks the flexibility which characterizes vector control.

Along with the various types of control which have experienced considerable growth in recent decades, the socalled sliding mode control (SMC) finds a good place in the literature, [10-12]. Since then, the spectrum of its use has been broadened to a larger class of systems including linear, nonlinear, discrete, multivariate and imprecise model systems. Thus, it has gained great popularity due to its simplicity and efficiency. This is because it is a non-linear control based on the switching of a function of the state variables. Therefore, the commutations are used to create a sliding hypersurface, the purpose of which is to force the dynamics of the system to correspond with that defined by the hypersurface equation.

The algorithm (SOSMC), overcomes some disadvantage of the classical SMC, [13-16]. This reduces undulations, known as chattering; it can damage the actuators by too frequent oscillations and adversely affect the operation and performance of the system, [20-24]. Nevertheless, the drawback of the SOSMC algorithm is the difficulty of working out the gains of the sign function. Among attention has been paid to combining this technique with artificial intelligence algorithms, [25-26]. This association links the benefit of the uncertainties and disturbances of the SMC with those of the speed and the correct trajectory of the intelligent control, makes it possible to overcome the problems of chattering the sliding mode control low.

The objective of this article is to propose a robust controller, which improves the quality of the energy produced and the energy efficiency. A robust FSOSMC of the DFIG is proposed; this technique is able to work under parametric uncertainty and reduces fluctuations in powers.

\section{DFIG Modelling}

The following system of equations describes the global modelling of the DFIG in the Park reference frame. The stator and rotor voltage equations are defined by, [2]:

$$
\left\{\begin{array}{l}
\mathrm{V}_{\mathrm{ds}}=\mathbf{R}_{\mathrm{s}} \mathbf{I}_{\mathrm{ds}}+\frac{\mathrm{d} \varphi_{\mathrm{ds}}}{\mathrm{dt}}-\omega_{\mathrm{s}} \varphi_{\mathrm{qs}} \\
\mathrm{V}_{\mathrm{qs}}=\mathbf{R}_{\mathrm{s}} \mathbf{I}_{\mathrm{qs}}+\frac{\mathrm{d} \varphi_{\mathrm{qs}}}{\mathrm{dt}}+\omega_{\mathrm{s}} \varphi_{\mathrm{ds}} \\
\mathrm{V}_{\mathrm{dr}}=\mathbf{R}_{\mathrm{r}} \mathbf{I}_{\mathrm{dr}}+\frac{\mathrm{d} \varphi_{\mathrm{dr}}}{\mathrm{dt}}-\omega_{\mathrm{r}} \varphi_{\mathrm{qr}} \\
\mathrm{V}_{\mathrm{qr}}=\mathbf{R}_{\mathrm{r}} \mathbf{I}_{\mathrm{qr}}+\frac{\mathrm{d} \varphi_{\mathrm{qr}}}{\mathrm{dt}}+\omega_{\mathrm{r}} \varphi_{\mathrm{dr}}
\end{array}\right.
$$

The stator and rotor fluxes are expressed by:

$$
\left\{\begin{array}{l}
\varphi_{\mathrm{ds}}=\mathrm{L}_{\mathrm{s}} \mathrm{I}_{\mathrm{ds}}+\mathrm{MI}_{\mathrm{dr}} \\
\varphi_{\mathrm{qs}}=\mathrm{L}_{\mathrm{s}} \mathrm{I}_{\mathrm{qs}}+\mathrm{MI}_{\mathrm{qr}} \\
\varphi_{\mathrm{dr}}=\mathrm{L}_{\mathrm{r}} \mathrm{I}_{\mathrm{dr}}+\mathrm{MI}_{\mathrm{ds}} \\
\varphi_{\mathrm{qr}}=\mathrm{L}_{\mathrm{r}} \mathrm{I}_{\mathrm{qr}}+\mathrm{MI}_{\mathrm{qs}}
\end{array}\right.
$$

The powers are given by:

$$
\begin{aligned}
& \mathrm{P}_{\mathrm{s}}=\left(\mathrm{V}_{\mathrm{ds}} \mathrm{I}_{\mathrm{ds}}+\mathrm{V}_{\mathrm{qs}} \mathrm{I}_{\mathrm{qs}}\right) \\
& \mathrm{Q}_{\mathrm{s}}=\left(\mathrm{V}_{\mathrm{qs}} \mathrm{I}_{\mathrm{ds}}-\mathrm{V}_{\mathrm{ds}} \mathrm{I}_{\mathrm{qs}}\right)
\end{aligned}
$$

The active and reactive power is given by:

$$
\begin{aligned}
& P_{\mathrm{s}}=-\left(\mathrm{V}_{\mathrm{s}} \frac{\mathrm{M}}{\mathrm{L}_{\mathrm{s}}} \mathrm{I}_{\mathrm{qr}}\right) \\
& \mathrm{Q}_{\mathrm{s}}=\left(\frac{\mathrm{V}_{\mathrm{s}}^{2}}{\mathrm{~L}_{\mathrm{s}} \mathrm{w}_{\mathrm{s}}}-\mathrm{V}_{\mathrm{s}} \frac{\mathrm{M}}{\mathrm{L}_{\mathrm{s}}} \mathrm{I}_{\mathrm{dr}}\right)
\end{aligned}
$$

\section{Second Order Sliding Mode Approach Modelling}

Despite the effectiveness sliding mode to robustness to disturbances and model uncertainties, but there still remains a problem present in the sliding mode, Among the solutions proposed to problems the appearance of the phenomenon of chattering caused by the discontinuous part of the system, there is a technique which can eliminate the disadvantage of this method which is called the Super-twisting algorithm, [9].

\subsection{Super-twisting algorithm}

We assumed a system with relative degree such as, [15]:

$$
\dot{s}=\hbar(t, x)+\gamma(t, x) u
$$

It is implied that:

$$
0<\Gamma_{m} \leq \gamma(t, x) \leq \Gamma_{M} \text { et }|\hbar(t, x)| \leq \mathcal{H} \text {. }
$$

$$
\Gamma_{m,} \Gamma_{M} \text { et } \mathcal{H}_{a} \text { Are positive constants. }
$$

The STA when applied to the system (6) drives s and in finite time by means of an absolutely continuous control in the presence of disturbances having a known limit. Smooth control $u(t)$ is a combination of two terms. It is defined by the following control law, [14]:

We will drive $s$ and $s{ }^{*}$ in finite time by mechanism of an absolutely continuous control in the bother presence having a known limit by applying the STA to the system, we find regular control $u(t)$ is a combination of two terms. It is defined by the succeeding control law:

$$
u(t)=u_{1}(t)+u_{2}(t)
$$

With:

$$
\tilde{u}_{1}= \begin{cases}-u & \mid u \|>1 \\ -\alpha \operatorname{sign}(s) & \mid u \| \leq 1\end{cases}
$$




$$
u_{2}= \begin{cases}-\beta\left|s_{0}\right|^{k} \operatorname{sign}(s) & |s|>s_{0} \\ -\beta|s|^{k} \operatorname{sign}(s) & |s| \leq s_{0}\end{cases}
$$

For the convergence in finite time about the sliding surface we have the corresponding adequate conditions are, [14]:

$$
\alpha>\frac{\mathscr{H}}{\Gamma_{m}}>0, \quad \beta^{2} \leq \frac{4 \mathscr{H} \Gamma_{m}(\alpha+\mathscr{H})}{\Gamma_{m}^{\mathrm{B}}(\alpha-\mathcal{H})}, 0<k \leq 0.5
$$

The two terms of equation (7) are successively the integral of a discontinuous function with sliding variable and the continuous function with sliding variable. As prescribed in the control law (7), the STA does not require to estimate the sign derivative surface ( $\$$ ). If $\mathrm{k}=1$ is used in command law (9), a stable exponential SOSMC algorithm emerges. The choice of $\mathrm{k}=0.5$ assured the finite-time convergence of $\mathrm{s}$ and $s$.

The elaboration of the STA is given as follows, [14]:

$$
\left\{\begin{array}{l}
\mathrm{u}_{\mathrm{st}}(\mathrm{t})=-\alpha\left|\mathrm{S}_{\Omega}\right|^{1 / 2} \operatorname{sign}\left(\mathrm{S}_{\Omega}\right)+\mathrm{u}_{1}(\mathrm{t}) \\
\dot{\mathrm{u}}_{1}(\mathrm{t})=-\beta \operatorname{sign}\left(\mathrm{S}_{\Omega}\right)
\end{array}\right.
$$

Where $\alpha$ and $\beta$ are positive limits constants.

\subsection{Stator active power control}

The active power regulation surface has taken term as:

$$
\mathrm{S}(\mathrm{P})=\mathrm{P}_{\mathrm{s}-\mathrm{ref}}-\mathrm{P}_{\mathrm{s}}
$$

The second derivative of equation (12) offer us:

$$
\ddot{S}\left(P_{\mathrm{S}}\right)=\ddot{P}_{s_{-} r e f}-\frac{V_{S} \mathrm{M}}{L_{S} L_{\mathrm{r}} \sigma}\left(\dot{\mathrm{V}}_{r q}-\mathrm{R}_{r} \dot{\mathrm{i}}_{r q}\right)
$$

By replacement the term $\dot{\mathrm{i}}_{r q}$ in equation (13), we find:

$$
\ddot{S}\left(P_{\mathrm{S}}\right)=\underbrace{\ddot{P}_{s \_r e f}-\frac{V_{S} \mathrm{M}}{L_{s} \mathrm{~T}_{\mathrm{r}} \sigma} \mathrm{K}_{1} \mathrm{i}_{\mathrm{rq}}+\frac{V_{S} \mathrm{M}}{L_{S} \mathrm{~T}_{\mathrm{r}} \sigma} \mathrm{K}_{2} \mathrm{i}_{\mathrm{rd}}-\frac{V_{S} \mathrm{M}}{L_{S} L_{\mathrm{r}} \mathrm{T}_{\mathrm{r}} \sigma^{2}} \mathrm{~V}_{r q}}_{\hbar(\mathrm{t}, \mathrm{x}, \mathrm{u})}+\underbrace{\frac{V_{S} \mathrm{M}}{L_{S} L_{\mathrm{r}} \sigma}}_{\gamma(\mathrm{t}, \mathrm{x}, \mathrm{u})} \dot{\mathrm{V}}_{r q}
$$

With:

$$
\mathrm{K}_{1}=\frac{1}{\sigma}\left(\frac{1}{\mathrm{~T}_{\mathrm{r}}}+\frac{\mathrm{M}^{2}}{L_{\mathrm{r}} L_{\mathrm{s}} \mathrm{T}_{\mathrm{s}}}\right), \mathrm{K}_{2}=\mathrm{gw}_{\mathrm{s}}
$$

Consequently:

$$
\mathrm{I}_{\mathrm{rq}_{-} \mathrm{P}}^{\mathrm{n}}=-\alpha_{1}\left|\mathrm{~S}_{\mathrm{P}_{\mathrm{s}}}\right|^{\frac{1}{2}} \operatorname{sign}\left(\mathrm{S}_{\mathrm{P}_{\mathrm{s}}}\right)-\beta_{1} \int \operatorname{sign}\left(\mathrm{S}_{\mathrm{P}_{\mathrm{s}}}\right) \mathrm{dt}
$$

$\alpha 1$ and $\beta 1$ are constants.

\subsection{Stator reactive power control}

The reactive power regulation surface has taken term as:

$$
\mathrm{S}(\mathrm{Q})=\mathrm{Q}_{\mathrm{s}-\mathrm{ref}}-\mathrm{Q}_{\mathrm{s}}
$$

The second derivative of equation (16) offer us:

$$
\ddot{S}\left(Q_{\mathrm{S}}\right)=\ddot{\mathrm{Q}}_{s_{-} r e f}+\frac{V_{s} \mathrm{M}}{L_{s} L_{\mathrm{r}} \sigma}\left(\dot{\mathrm{V}}_{r d}-\mathrm{R}_{r} \dot{\mathrm{i}} r d\right)
$$

By replacement the term ${ }^{\vdots}$ rd in equation (17), we find:

$$
\ddot{S}\left(Q_{\mathrm{s}}\right)=\underbrace{\ddot{Q}_{s_{-} r e f}+\frac{V_{s} \mathrm{M}}{L_{s} \mathrm{~T}_{\mathrm{r}}^{2} \sigma^{2}} \mathrm{i}_{\mathrm{rd}}+\frac{V_{s} \mathrm{M}}{L_{s} \mathrm{~T}_{\mathrm{r}} \sigma} \mathrm{K}_{2} \mathrm{i}_{\mathrm{rq}}-\frac{V_{s} \mathrm{M}}{L_{s} L_{\mathrm{r}} \mathrm{T}_{\mathrm{r}} \sigma^{2}} \mathrm{~V}_{r d}}_{\hbar(\mathrm{t}, \mathrm{x}, \mathrm{u})}+\underbrace{\frac{V_{s} \mathrm{M}}{L_{s} L_{\mathrm{r}} \sigma}}_{\gamma(\mathrm{t}, \mathrm{x}, \mathrm{u})} \dot{\mathrm{V}}_{r d}
$$

With:

$$
\mathbf{K}_{2}=\mathbf{g w}_{\mathrm{s}}
$$

$$
e=i_{r q \_r e f}-i_{r q}
$$

The slide surface of the quadrature rotor current is determined as follows:

Its second derivative provide us: $\alpha 2$ and $\beta 2$ are constants.

\subsection{Quadrature rotor current control}

The quadrature rotor current error irq is taken term as:
(19) $\ddot{S}\left(i_{\mathrm{rq}}\right)=\ddot{\mathrm{i}_{r q} r e f}-\left[-\frac{1}{\sigma}\left(\frac{1}{\mathrm{~T}_{\mathrm{r}}}+\frac{\mathrm{M}^{2}}{L_{\mathrm{r}} L_{\mathrm{S}} \mathrm{T}_{\mathrm{s}}}\right) \dot{\mathrm{i}}_{r q}-\mathrm{gw}_{\mathrm{s}} \dot{\mathrm{i}}_{r d}+\frac{1}{\sigma \mathrm{L}_{\mathrm{r}}} \dot{\mathrm{V}}_{r q}\right]$

By replacement the terms $\dot{\mathrm{i}}_{r d}$ and $\dot{\mathrm{i}}_{r q}$ in equation (22), we find: 


$$
\ddot{S}\left(i_{\mathrm{rq}}\right)=\underbrace{\ddot{\mathrm{i}}_{r q_{-} r e f}-\left(\mathrm{K}_{1}^{2}-\mathrm{K}_{2}^{2}\right) \mathrm{i}_{\mathrm{rq}}-\left(\mathrm{K}_{1} \mathrm{~K}_{2}+\frac{\mathrm{K}_{2}}{\sigma \mathrm{T}_{\mathrm{r}}}\right) \mathrm{i}_{\mathrm{rd}}-\frac{1}{\sigma \mathrm{L}_{\mathrm{r}}} \mathrm{K}_{1} \mathrm{~V}_{\mathrm{rq}}-\frac{1}{\sigma \mathrm{L}_{\mathrm{r}}} \mathrm{K}_{2} \mathrm{~V}_{\mathrm{rd}}}_{\hbar(\mathrm{t}, \mathrm{x}, \mathrm{u})}-\frac{1}{\sigma \mathrm{L}_{\mathrm{r}}} \dot{\mathrm{V}}_{r q}
$$

With:

$$
\mathrm{K}_{1}=\frac{1}{\sigma}\left(\frac{1}{\mathrm{~T}_{\mathrm{r}}}+\frac{\mathrm{M}^{2}}{L_{\mathrm{r}} L_{\mathrm{s}} \mathrm{T}_{\mathrm{s}}}\right), \mathrm{K}_{2}=\mathrm{gW}_{\mathrm{S}}
$$

Hence:

$$
\mathrm{V}_{\mathrm{rq}_{-} \mathrm{irq}}^{\mathrm{n}}=-\alpha_{3}\left|\mathrm{~S}_{\mathrm{i}_{\mathrm{rq}}}\right|^{\frac{1}{2}} \operatorname{sign}\left(\mathrm{S}_{\mathrm{i}_{\mathrm{rq}}}\right)-\beta_{3} \int \operatorname{sign}\left(\mathrm{S}_{\mathrm{i}_{\mathrm{rq}}}\right) \mathrm{dt}
$$

\subsection{Direct rotor current control}

The front rotor current error ird is distinct by:

$$
\begin{aligned}
& e=i_{r d \_r e f}-i_{r d} \\
& \mathrm{~K}_{1}=\frac{1}{\sigma}\left(\frac{1}{\mathrm{~T}_{\mathrm{r}}}+\frac{\mathrm{M}^{2}}{L_{\mathrm{r}} L_{\mathrm{s}} \mathrm{T}_{\mathrm{S}}}\right) \mathrm{K}_{2}=\mathrm{gw}_{\mathrm{s}}
\end{aligned}
$$$$
\ddot{S}\left(i_{\mathrm{rd}}\right)=\underbrace{\ddot{\mathrm{i}_{r q} q_{-} r e f}-\left(\frac{1}{\sigma^{2} \mathrm{~T}_{\mathrm{r}}^{2}}+\mathrm{K}_{2}^{2}\right) \mathrm{i}_{\mathrm{rd}}+\left(\mathrm{K}_{1} \mathrm{~K}_{2}+\frac{\mathrm{K}_{2}}{\sigma \mathrm{T}_{\mathrm{r}}}\right) \mathrm{i}_{\mathrm{rq}}-\frac{1}{\left(\sigma \mathrm{T}_{\mathrm{r}}\right)^{2}} \mathrm{~V}_{\mathrm{rd}}+\frac{1}{\sigma \mathrm{L}_{\mathrm{r}}} \mathrm{K}_{2} \mathrm{~V}_{\mathrm{rq}}}_{\hbar(\mathrm{t}, \mathrm{x}, \mathrm{u})}-\frac{1}{\sigma \mathrm{L}_{\mathrm{r}}} \dot{\mathrm{V}}_{r d}
$$

As thus we find:

$$
\mathrm{V}_{\mathrm{rq} \_ \text {ird }}^{\mathrm{n}}=-\alpha_{4}\left|\mathrm{~S}_{\mathrm{i}_{\mathrm{rd}}}\right|^{\frac{1}{2}} \operatorname{sign}\left(\mathrm{S}_{\mathrm{i}_{\mathrm{rd}}}\right)-\beta_{4} \int \operatorname{sign}\left(\mathrm{S}_{\mathrm{i}_{\mathrm{rd}}}\right) \mathrm{dt}
$$

\section{A Robust Control Scheme Using Fuzzy SOSMC}

The combination of the two "Sliding Mode and Fuzzy Logic" methods enables the introduction of highperformance technology into the system's dynamic performance and improves the reduction of residual vibration at high frequencies. The replacement of the "sign" function by a fuzzy inference system facilitates the SOSMC control procedure. Thus, with the application of this proposed strategy, equation (11) becomes:
The front surface sliding of the rotor current is determined as follows:

$$
S\left(i_{\text {rd }}\right)=e=i_{\text {rd_ref }}-i_{r d}
$$

Its second derivative provide us:

$\ddot{S}\left(i_{\mathrm{rd}}\right)=\ddot{\mathrm{i}}_{r d} \_r e f-\left[-\frac{1}{\sigma \mathrm{T}_{\mathrm{r}}} \dot{\mathrm{i}}_{r d}+\mathrm{gw}_{\mathrm{s}} \dot{\mathrm{i}}_{r q}+\frac{1}{\sigma \mathrm{L}_{\mathrm{r}}} \dot{\mathrm{V}}_{r d}\right]$

By replacement the terms $\dot{\mathrm{i}}_{r d}$ and $\dot{\mathrm{i}}_{r q}$ in equation (27), we find:
$\left\{\begin{array}{l}\mathrm{u}_{\mathrm{st}}(\mathrm{t})=-\alpha\left|\mathrm{S}_{\Omega}\right|^{1 / 2} \operatorname{fuzzy}\left(\mathrm{S}_{\Omega}\right)+\mathrm{u}_{1}(\mathrm{t}) \\ \dot{\mathrm{u}}_{1}(\mathrm{t})=-\beta \operatorname{fuzzy}\left(\mathrm{S}_{\Omega}\right)\end{array}\right.$

\section{DFIG Modelling}

In order to confirm the effectiveness of the control structure recommended for the DFIG control system illustrated in Figure 1. The behaviour of the FSOSMC-SVM regulator controller is compared to SOSMC-SVM controller. The results of the simulations are granted for the two controllers under identical conditions. Separate modes of operation of the suggested algorithm were presented, namely simulation results with and without parametric uncertainties. In each test, the powers, voltage, stator and rotor currents and the current harmonic distortion THD are presented. The parameters of the DFIG are reported in, [7].

The block diagram of the considered FSOSMC is shown in Fig.1. 


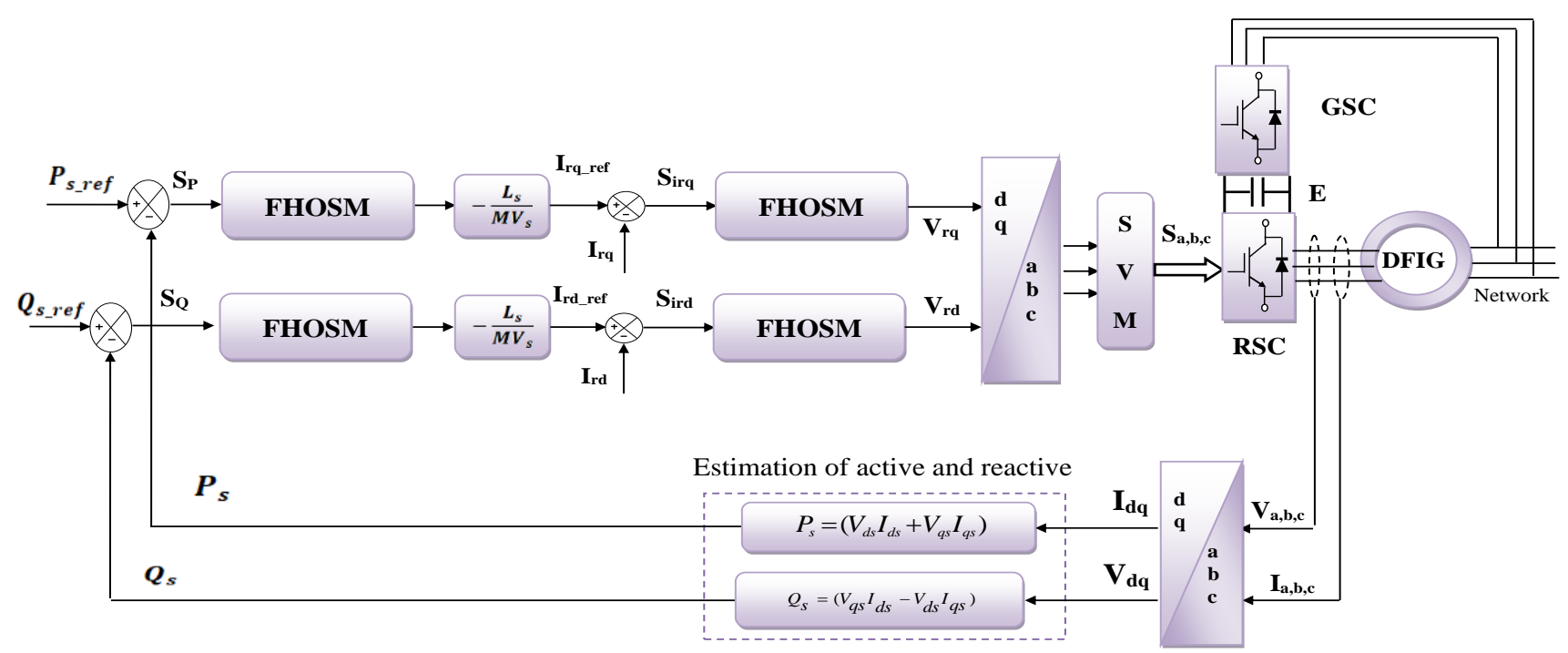

Fig. 1. Diagram of FSOSMC algorithm developed on DFIG.

\subsection{Results of simulation without system uncertainties}

The simulation results obtained in Figures (2-5) show that the command developed by FSOSMC achieves good decoupling, good power adjustment and good tracking of the imposed reference values. In addition, the comparison between the results from the SOSMC shows a great resemblance with respect to the dynamic behaviour. However, the SOSMC has two main advantages, namely the robustness and the ease of the numerical implementation of the control law. The results obtained give us a good idea of the behaviour of the different quantities of the system. The contribution of the introduction of the fuzzy controller was manifested in a marked decrease in the phenomenon of (Chattering)

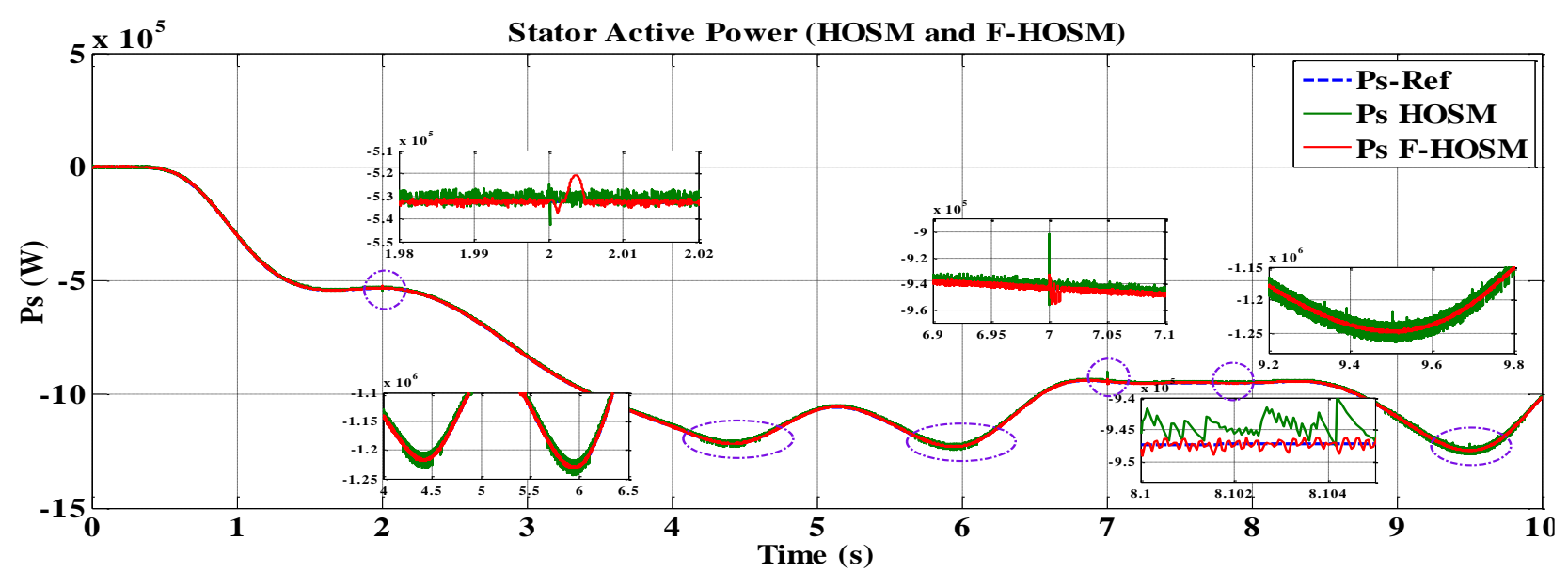

Fig. 2. FSOSMC and SOSMC response of active power.

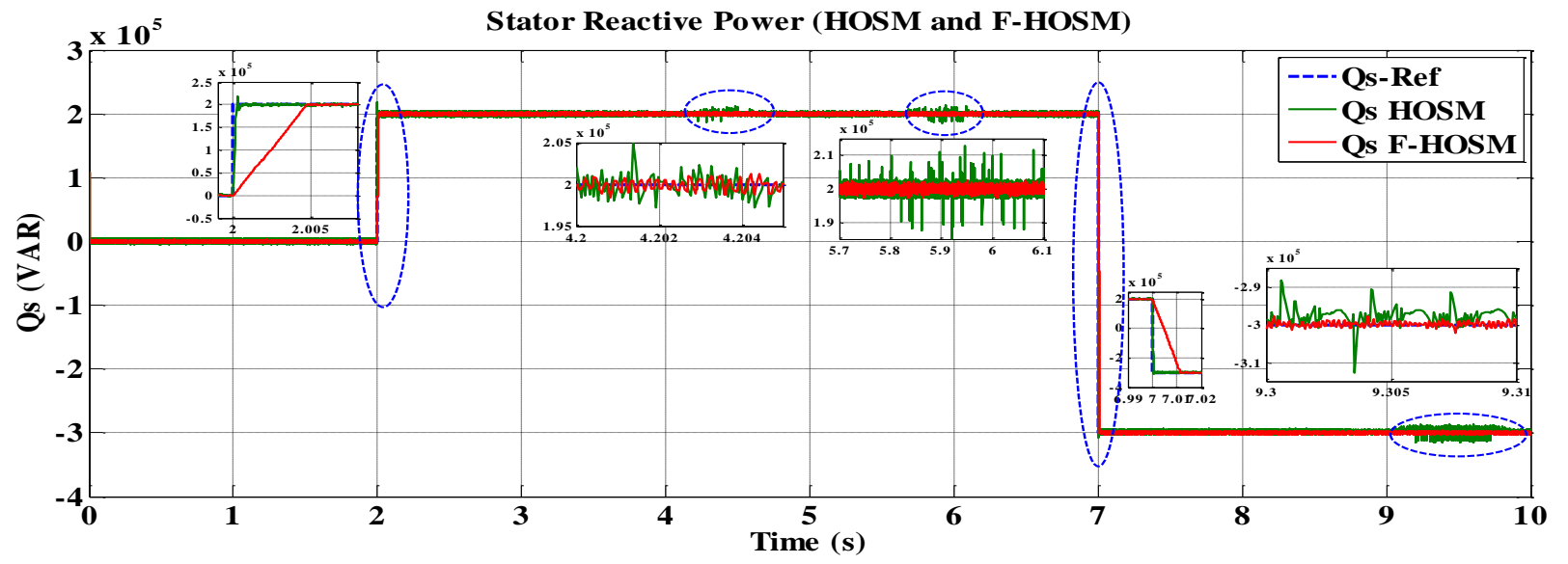


Fig. 3. FSOSMC and SOSMC reactive power response.

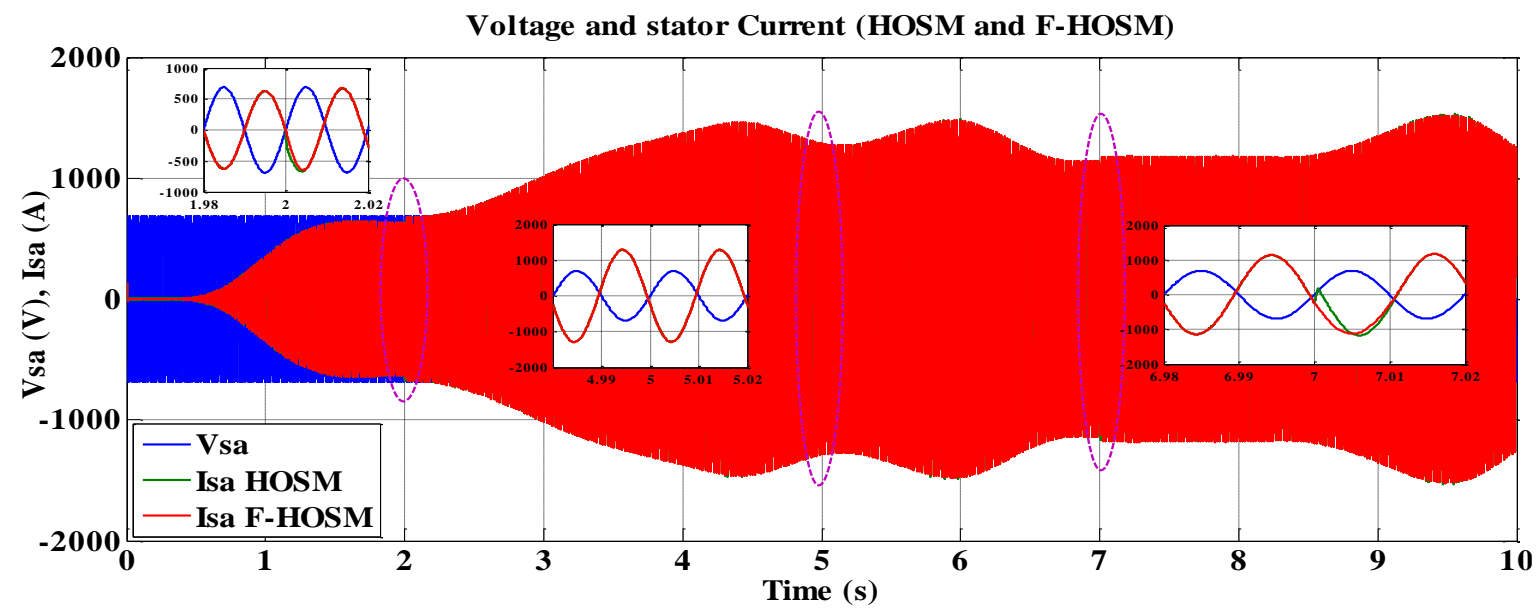

Fig. 4. FSOSMC and SOSMC stator current response.

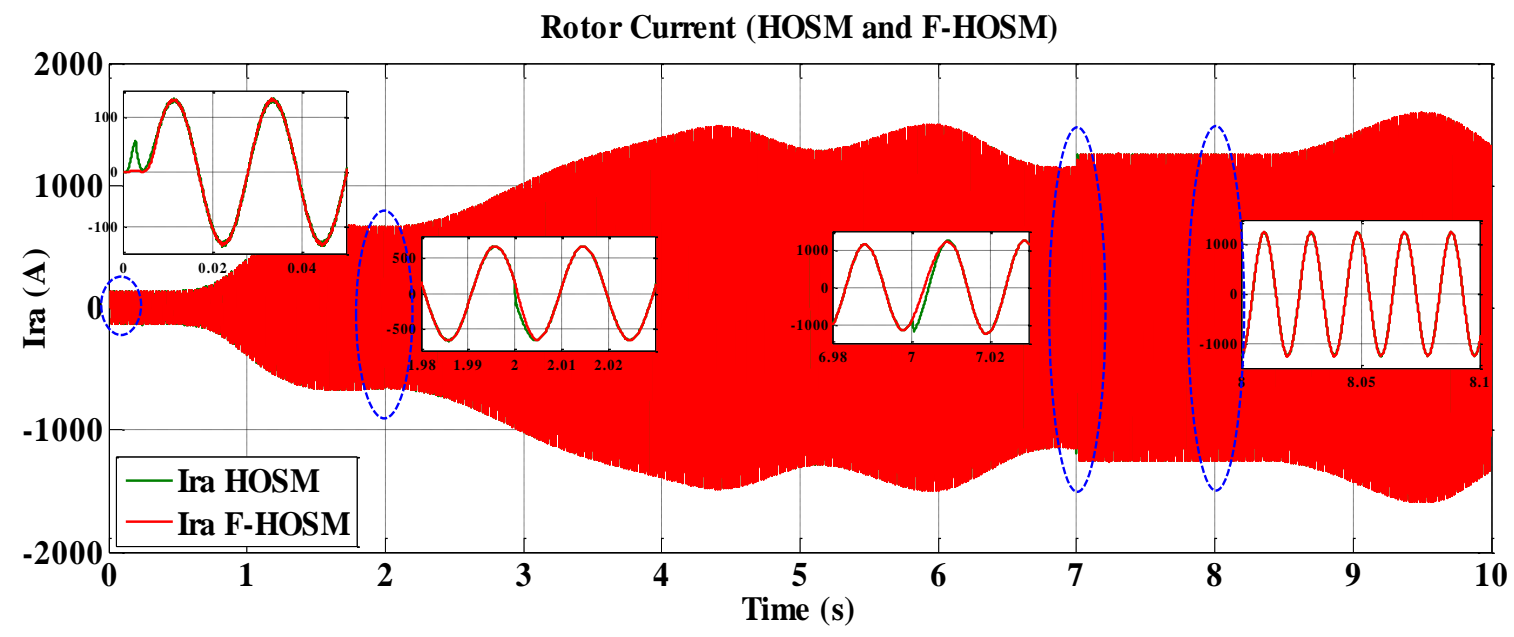

Fig. 5. FSOSMC and SOSMC rotor current response.

5.2. Results of simulation in the presence of system uncertainties

In this test, the influence of the parametric variation on the decoupling between the active and reactive power is studied. For this test, the Rr and Lr of the DFIG is increased by $+150 \%$ at $t=7.5$ s. Figure 6 , illustrate the stator active power and Figure 7 presents the stator reactive power. The rotor resistance variation has no influence on the decoupling between active and reactive powers in FSOSMC algorithm compared to the SOSMC algorithm.

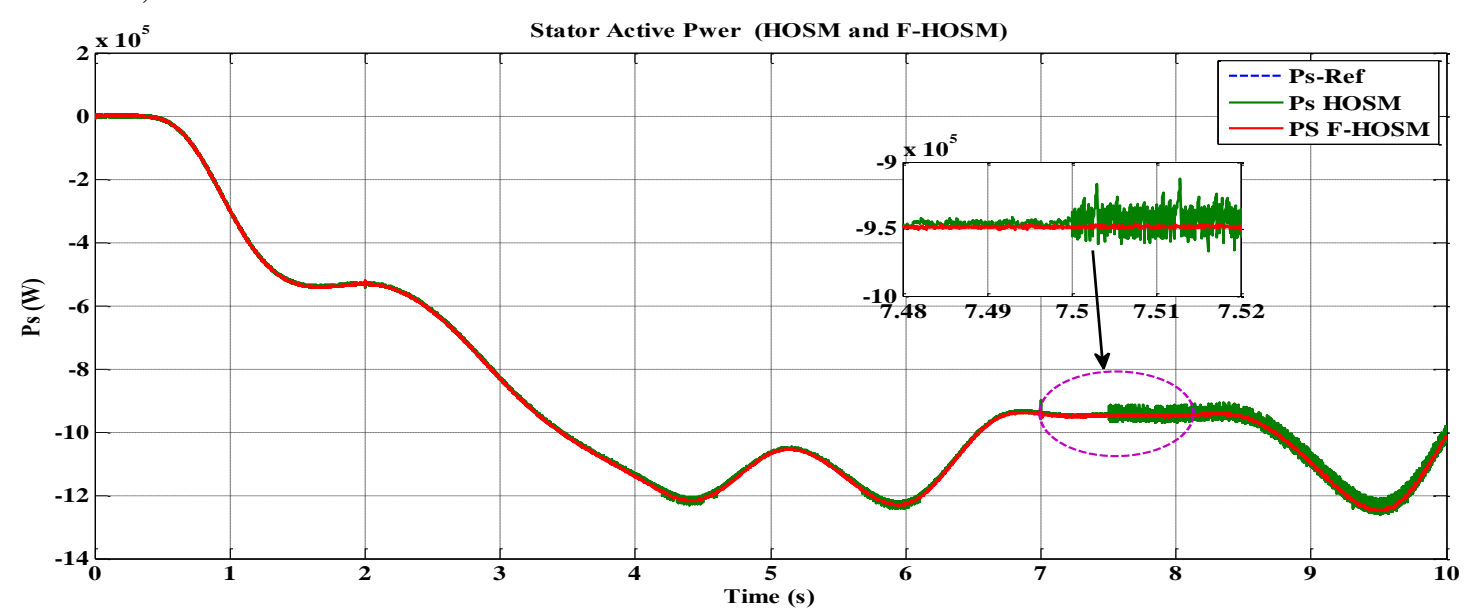

Fig. 6. Simulation of active power in the presence of system uncertainties; 


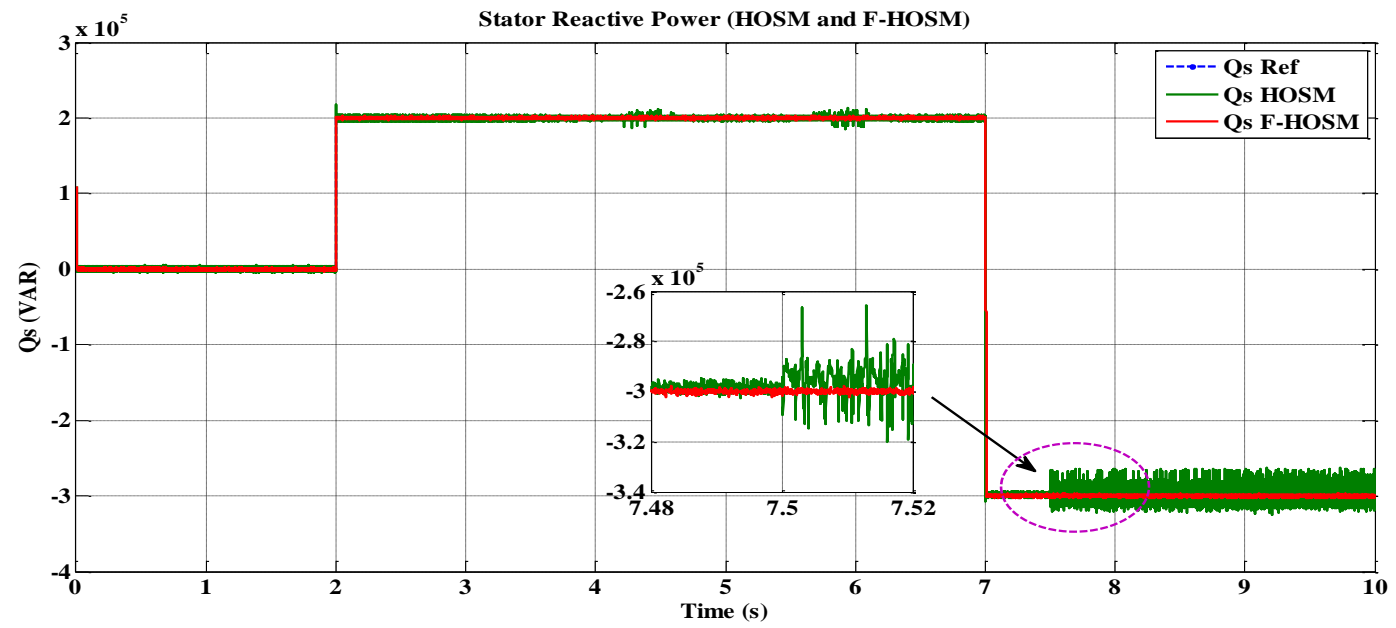

Fig. 7. Simulation of reactive power in the presence of system uncertainties

There is a great improvement the oscillations which it presented in the absence of the fuzzy controller no longer exist and the phenomenon of (Chattering) is negligible, this highlights the robustness of the contribution of fuzzy logic to the sliding mode.
Figure (8) illustrates the harmonic spectrum of the stator current in a phase A. It can be illustrated that the harmonic distortion rate of SOSMC is greater than that of FSOSMC.

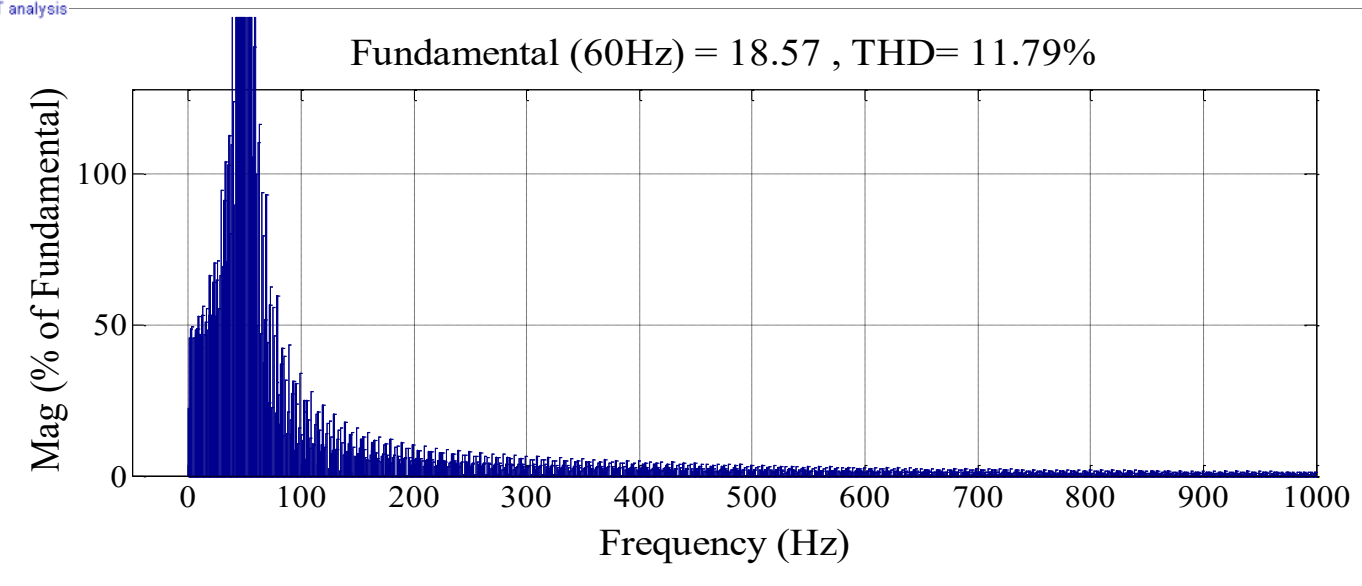

(a)

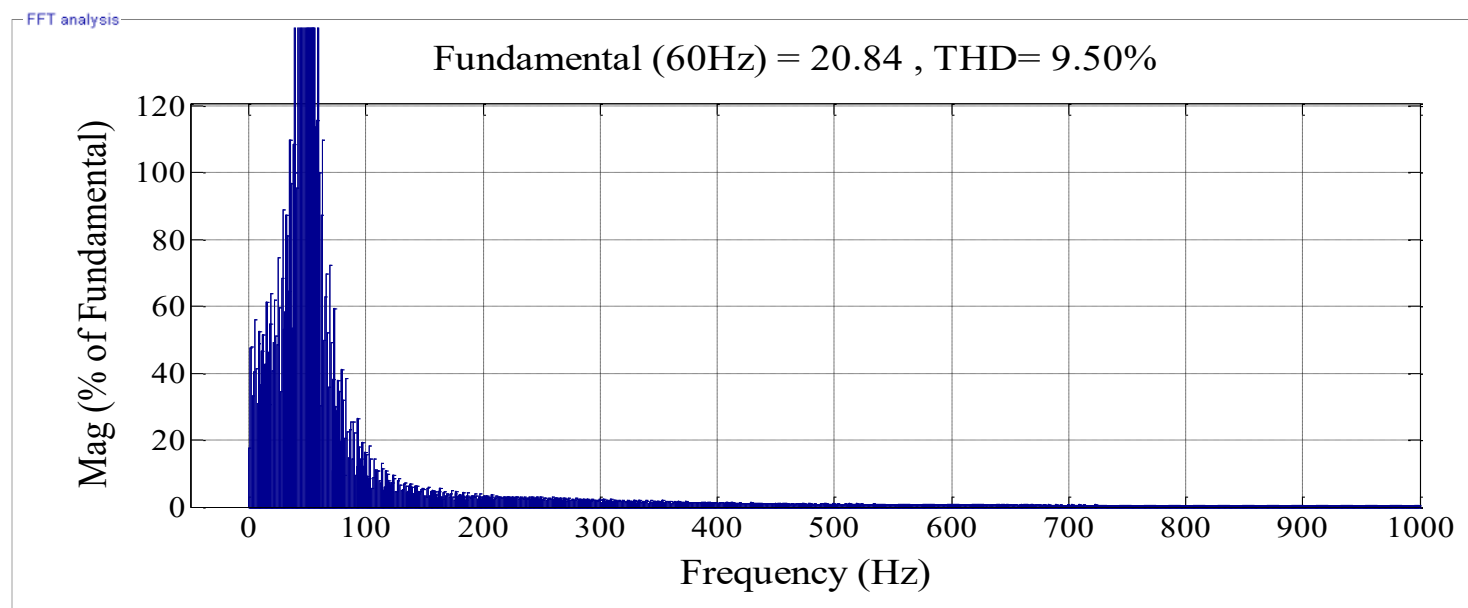

(b)

Fig. 8. Stator current: (a) SOSMC, (b) FSOSMC harmonic spectra. 
Table 1 presents the comparative evaluation of the proposed methods. The comparison among the two presented techniques for power control guaranty that the proposed (F-
HOSM) scheme gives much less chattering with a clear transient response.

Table 1. A comparative evaluation of the proposed methods.

\begin{tabular}{|l|c|c|}
\hline \multicolumn{1}{|c|}{ Approach } & HOSM & F-HOSM \\
\hline Robustness to parameters mismatch & Medium & Low \\
\hline Harmonic spectrum of stator current & High & Small chattering \\
\hline Chattering & Considerable chattering & time \\
\hline $\begin{array}{l}\text { Transient performance of the active } \\
\text { power }\end{array}$ & Fast with low settling time & $\begin{array}{c}\text { Relatively fast with low settling } \\
\text { tising time of the active power }\end{array}$ \\
\hline $\begin{array}{l}\text { Transient performance of the reactive } \\
\text { power }\end{array}$ & Fast with low settling time & $\begin{array}{c}\text { Relatively fast with low settling } \\
\text { time }\end{array}$ \\
\hline Rising time of the reactive power & $0.0009 \mathrm{~s}$ & $0.0045 \mathrm{~s}$ \\
\hline $\begin{array}{l}\text { Implementation } \\
\text { Complexity }\end{array}$ & Low & Low \\
\hline
\end{tabular}

\section{Conclusion}

In this work, we are interested in the study and simulation of a wind power conversion chain based on FSOSMC. The goal being energy optimization, for this purpose we have adopted control strategies for the control of the DFIG at the different conversion stages. A FSOSMC approach was developed for this purpose and a super twisting algorithm was the subject of our control strategy. The tool used for to achieve this goal is the software Simulink/ Matlab it is in this context that this work was carried out. This command was used for the regulation of the powers of the DFIG. Our control methodology linked to systems with variable structures, the aim of which is to overcome the drawbacks of conventional controls. Therefore, to conclude that the FSOSMC technique used for the desired control of the system has led to good performance. The results obtained clearly show the validity of the approach followed. They also show that the control strategy developed is well suited to the problems of tracking trajectories, respecting electromechanical constraints and being robust with respect to parametric uncertainties. In many cases, the latter offers certain advantages:

Robustness in relation to variations in system parameters.

A very efficient dynamic (acceptable response time and practically zero stationary error). law.

Simplicity of the implementation of the switching

\section{References}

[1] N.K.S. Naidu, B. Singh, "Grid-Interfaced DFIG-Based Variable Speed Wind Energy Conversion System With Power Smoothening". IEEE Trans. Sustain. Energy, 8, 51-58. 2017.
[2] G. Abad, J. Lopez, M. Rodriguez, L. Marroyo, G. Iwanski, Doubly Fed Induction Machine: Modeling and Control for Wind Energy Generation; JohnWiley \& Sons: Hoboken, NJ, USA, Volume 85. 2011;

[3] L. Xu, Y. Wang, "Dynamic modeling and control of DFIG-based wind turbines under unbalanced network conditions". IEEE Trans. Power Syst, 22, 314-323, 2007.

[4] Y. Zhang, Z. Li, \& W. Xu, A novel three-vectors-based predictive direct power control of doubly fed induction generator for wind energy applications. In Energy Conversion Congress and Exposition (ECCE), pp. 793800. 2012.

[5] B. Peng, F. Zhang, J. Liang, L. Ding, Z. Liang, Q. Wu, coordinated control strategy for the short-term frequency response of a DFIG-ES system based on wind speed zone classification and fuzzy logic control. Int. J. Electr. Power Energy Syst., 107, 363-378. 2019.

[6] F. Boumaraf, T. Boutabba, S. Belkacem, Dual direct torque control of doubly fed induction machine using second order sliding mode control, Journal of Measurements in Engineering, Vol. 9, Issue 1, , pp. 1-12. 2021.

[7] F. Mazouz, S. Belkacem, I. Colak, S. Drid, “Adaptive direct power control for double fed induction generator used in wind turbine", International Journal of Electrical Power \& Energy Systems 114, 2020.

[8] A. Mohamed Eltamaly, M. Al-Saud, K. Sayed and A. G. Abo-Khali, "Sensorless Active and Reactive Control for DFIG Wind Turbines Using Opposition-Based" Learning Technique, Sustainability 2020,

[9] F. Mazouz, S. Belkacem, I. Colak, S. Drid, "Direct Power Control of DFIG by Sliding Mode Control and Space Vector Modulation", 7th International conference on system and control, IEEE (ICSC), Valencia - Spain, October, 24-26, 2018. 
[10] J. Hu, H. Nian, B. Hu, Y. He, \& Q.Z. Zhu, "Direct active and reactive power regulation of DFIG using sliding-mode control approach". IEEE Transactions on Energy Conversion, Vol 25, 2010.

[11] V. Utkin, J.L. Hoon, "Chattering Problem in Sliding Mode Control Systems", international Workshop on Variable Structure Systems, VSS'06. 2006.

[12] R.F. Abdelgoui, M. Zerikat and R. Tale, "Conception d'un contrôleur à logique flou basé sur la théorie des modes glissants appliquée à la machine asynchrone triphasée, Revue des Energies Renouvelables Vol. 21 $\mathrm{N}^{\circ} 1, \mathrm{pp} 11$ - 18. 2018.

[13] S. Mefoued, "A second order sliding mode control and a neural network to drive a knee joint actuated orthosis," Neurocomputing, vol. 155, pp. 71-79, 2015.

[14] O. Moussa, A. Rachid, and B. Said. "Super twisting sliding mode control for brushless doubly fed induction generator based on WECS", ISSN 0975-6809”. International Journal of System Assurance Engineering and Management volume 10: pp. 1145-1157. 2019.

[15] P. Gu, X. Wang, M. Reitz, "High order sliding mode control of permanent magnet synchronous generatorbased wind energy conversion systems". In Proceedings of the IEEE Energy Conversion Congress and Exposition (ECCE), Milwaukee, WI, USA, 18-22; pp. 1-8. September 2016.

[16] I.L. Borlaug, "Higher-Order Sliding Mode Control". Master's Thesis, Norwegian University of Science and Technology, Trondheim, Norway, June 2017.

[17] S. S. Ullah, Z. Ali, N. Ullah, J.S. Ro, “A Super Twisting Fractional Order Terminal Sliding Mode Control for DFIG-Based Wind Energy Conversion", System,Energies, 13(9),2020.

[18] N. Bounasla, K.E. Hemsas, "Second order sliding mode control of a permanent magnet synchronous motor". In Proceedings of the IEEE 14th International Conference on Sciences and Techniques of Automatic Control \& Computer Engineering (STA), Sousse, Tunisia, 20-22 pp. 535-539. December 2013.

[19] A. Dendouga, "Conventional and Second Order Sliding Mode Control of Permanent Magnet Synchronous Motor Fed by Direct Matrix Converter", Comparative Study Energies, 13(19), 5093. 2020.

[20] L. Ouada, S. Benaggoune, S. Belkacem, "Neuro-fuzzy Sliding Mode Controller Based on a Brushless Doubly Fed Induction Generator", International Journal of Engineering (IJE), IJE TRANSACTIONS B: Applications Vol. 33, No. 2, 2020.

[21] D. Kairous, B. Belmadani, "Robust fuzzy-second order sliding mode based direct power control for voltage source converter". International Journal of Advanced Computer Science and Applications, 6, 167-175. 2015.

[22] N. Choug, S. Benaggoune, S. Belkacem, "Hybrid Fuzzy Reference Signal Tracking Control of a Doubly Fed Induction Generator", International Journal of
Engineering (IJE), IJE TRANSACTIONS A: Basics Vol. 33, No. 4, pp 567-574. April 2020.

[23] F. Mazouz, S. Belkacem, S. Drid, L. Chrifi-Alaoui and I. Colak, "Fuzzy Sliding Mode Control of DFIG applied to the WECS". Proceedings of the 8th International Conference on Systems and Control, Marrakech, Morocco, October 23-25, 2019.

[24] B. Kiyyour, "Hybrid fuzzy second order sliding mode control speed for Direct Torque Control of Dual Star Induction motor". Journal of Fundamental and Applied Sciences. 2019.

[25] X. Yuan, Z. Chen, Y. Yuan and Y. Huang, "Design of fuzzy sliding mode controller for hydraulic turbine regulating system via input state feedback linearization method", Energy, vol. 93, pp. 173-187, 2015.

[26] K.M. Arun Prasad, A. Unnikrishnan and N. Usha, 'Fuzzy Sliding Mode Control of a Switched Reluctance Motor', Global Colloquium in Recent Advancement and Effectual Researches in Engineering, Science and Technology, 'RAEREST', 2016. 